\title{
Irradiation stability and cytotoxicity of gold nanoparticles for radiotherapy
}

\author{
This article was published in the following Dove Press journal: \\ International Journal of Nanomedicine \\ 2 September 2009 \\ Number of times this article has been viewed
}

\section{Xiao-Dong Zhang' \\ Mei-Li Guo \\ Hong-Ying Wu' \\ Yuan-Ming Sun' \\ Yan-Qiu Ding' \\ Xin Feng' \\ Liang-An Zhang'}

'Institute of Radiation Medicine, Chinese Academy of Medical Sciences and Peking Union Medical College, Tianjin, People's Republic of China; 'Department of Physics, Tianjin Institute of Urban Construction, Tianjin, People's Republic of China
Correspondence: Xiao-Dong Zhang Institute of Radiation Medicine, Chinese Academy of Medical Sciences and Peking Union Medical College, Tianjin 300192,

People's Republic of China

Email xiaodongzhang@yahoo.cn

\begin{abstract}
Gold nanoparticles are promising as a kind of novel radiosensitizer in radiotherapy. If gold nanoparticles are shown to have good irradiation stability and biocompatibility, they would play an important role in radiotherapy. In this work, we investigated irradiation effects of gold nanoparticles under 2-10 kR gamma irradiation and cytotoxicity of gold nanoparticles with human K562 cells by using Cell Titre-Glo ${ }^{\mathrm{TM}}$ luminescent cell viability assay. The results revealed that gamma irradiation had not induced any obvious instability and size variations in gold nanoparticles. We found that gold nanoparticles showed excellent radiation hardness with an absorbed dose conversation factor of $9.491 \mathrm{rad} / \mathrm{R}$. Meanwhile, the surface plasmon resonance of gold nanoparticles was enhanced obviously after 2-10 kR gamma irradiation. Subsequently, cytotoxicity tests indicated that the extremely high concentration of gold nanoparticles could cause a sharp decrease in K562 cell viability, while the low concentration of gold nanoparticles had no obvious influence on the cell viability. Our results revealed that gold nanoparticles were stable under high-energy ray irradiation and showed concentration-dependent cytotoxicity.
\end{abstract}

Keywords: gold nanoparticles, gamma ray effects, colloids, cytotoxicity

\section{Introduction}

Gold nanoparticles (NPs) have attracted increasing interest in diagnosis and therapy of disease. ${ }^{1,2}$ Due to the strong and size-tunable surface plasmon resonance (SPR), fluorescence, and easy-surface functionalization, gold NPs have been widely used in biosensors, cancer cell imaging, photothermal therapy, and drug delivery. ${ }^{3-9}$ Today, gold NPs have been conceived as a type of radiosensitizer in radiotherapy because the strong photoelectric absorption and second electron caused by gamma or X-ray irradiation can accelerate DNA strand breaks. ${ }^{10-12}$ However, the advanced medical diagnoses instruments, such as X-ray, positron emission tomography, and computed tomography, are always closely related to high energy rays. Thus, the irradiation stability test for gold NPs becomes more and more important. In addition, the further cytotoxicity test for gold NPs is necessary for radiotherapy and drug delivery.

It is well known that gamma irradiation can induce defects of materials, such as color center, which is very useful for the fabrication of laser device and medical thermoluminescence dosimetry. ${ }^{13-15}$ However, gamma irradiation can also cause obvious instability and new optical transition of materials. ${ }^{16,17}$ Chung and colleagues showed that the $\mathrm{Ni} / \mathrm{SiC}$ film was seriously unstable and could cause severe reaction in interface by gamma irradiation. ${ }^{18}$ In the oxides, gamma irradiation can induce the oxygen-deficient centers, which can influence thermal stability and optical properties of materials. ${ }^{19,20}$ In nanomaterials, the influence induced by gamma irradiation is

submit your manuscript | www.dovepress.con 
being reported more often. Recently, Withers and colleagues reported that increasing the gamma irradiation dose induced an 80-fold decrease in photoluminescence in the quantum dots (QDs), which indicated that the QDs were unstable after being exposed to high energy rays. ${ }^{21}$ The results indicated that cancer cell imaging and biomarkers of CdSe QDs should be used cautiously before applying the irradiation stability test. A similar concern for gold NPs has emerged because radiotherapy always includes a high energy ray. However, the study of the stability and optical influence of gold NPs induced by high energy gamma ray irradiation has been neglected.

In addition, a key area for nanotechnology will be the assessment of health effects and toxicity of nanomaterials. The increasing toxicity of nanomaterials such as NPs, QDs, nanowires, and nanotubes has been reported..$^{22}$ The biosafety of metallic gold is well known and it has been used in vivo since the 1950s. However, functionalized gold NPs have shown obvious cytotoxicity. ${ }^{23}$ To clarify these problems, the cytotoxicity of gold NPs in human cells has been studied in detail and the results showed that gold NPs were nontoxic up to $250 \mathrm{mM}$ while the ionic gold showed obvious cytotoxicity at $25 \mathrm{mM} .^{24}$ Similar results were also reported in the recent radiotherapy of gold NPs in vitro. ${ }^{12}$ Nevertheless, a further cytotoxicity test at high gold concentrations is still essential because gold concentration in radiotherapy can be as high as $7 \mathrm{mg} / \mathrm{mL} .{ }^{10}$ Indeed, recent cytotoxicity tests showed that gold NPs were toxic at high concentrations. ${ }^{25}$ Thus, the cytotoxicity test will be helpful for further medical applications.

This work focuses on two aspects: whether gold NPs are stable under high energy gamma ray irradiation, and whether high gold concentration can influence the cell viability in vitro. Both aspects are related to the application of gold NPs in radiotherapy and health care.

\section{Materials and methods}

Gold NPs are fabricated by the classical method introduced by Turkevich. ${ }^{26} \mathrm{~A}$ volume of $100 \mathrm{~mL}$ of $0.01 \%$ chloroauric acid $\left(\mathrm{HAuCl}_{4} \cdot 4 \mathrm{H}_{2} \mathrm{O}\right)$ solution is refluxed and $5 \mathrm{~mL}$ of $1 \%$ sodium citrate solution added to the boiling solution. The reduction of gold ions by the citrate ions is completed after $5 \mathrm{~min}$. The solution is further boiled for $30 \mathrm{~min}$ and is then left to cool to room temperature. This method yields spherical particles with an average diameter of about $15 \mathrm{~nm}$. Although the actual value of the mean size might vary slightly from each preparation, the size distribution is found to be always about $12 \%$ of standard deviation. The size and morphology of gold NPs are analyzed by high-resolution field emission transmission electron microscopy (TEM) (Hitachi HF-2000; Hitachi, Guangzhou City, People's Republic of China) operating at $200 \mathrm{kV}$. Optical absorption spectra in wavelength range of $200-850 \mathrm{~nm}$ are measured with DU800 Spectrometer (Beckman Coulter, Fullerton, CA, USA) in a $5 \mathrm{ml}$ glass cuvette.

Gamma irradiation experiments are carried out in the Institute of Radiation Medicine, Chinese Academy of Medical Sciences (CAMS). The gold NPs are separated into four equal parts with $20 \mathrm{~mL}$. Subsequently, they are irradiated by ${ }^{137} \mathrm{Cs}$ with activity of $3600 \mathrm{Ci}$ and photon energy of $662 \mathrm{KeV}$. In clinical radiotherapy, the exposure dose of gamma ray is around 0.1 to $10 \mathrm{kR}$. Thus, the irradiated doses of gold NPs are arranged for 2, 4, 6, 8, and $10 \mathrm{kR}$. After gamma irradiation, the TEM and UV-Vis spectrometer were used to investigate the morphology and optical effect.

Human erythroleukemia cells (K562 cells) are cultured in RPMI-1640 medium (Sigma Aldrich, St. Louis, MO, USA), supplemented with 10\% heat-inactivated fetal bovine serum (FBS) and antibiotics $(100 \mathrm{mg} / \mathrm{mL}$ streptomycin and $100 \mathrm{U} / \mathrm{mL}$ penicillin) at $37{ }^{\circ} \mathrm{C}$ in humidified atmosphere with $5 \% \mathrm{CO}_{2}$. The cells (in culture medium) are dispensed in 96 -well plates $\left(90 \mathrm{~mL}\right.$ in each well containing $10^{4}$ cells per well). Gold NPs of $10 \mu \mathrm{L}$ are dissolved in culture medium and then $100 \mu \mathrm{L}$ blending are added to each well with different concentrations (18.75-600 $\mu \mathrm{g} / \mathrm{mL})$. The effect of the concentration of gold NPs is assessed using Cell Titre-Glo ${ }^{\mathrm{TM}}$ luminescent cell viability assay (Promega, Madison, WI, USA). This assay is a homogenous method of determining the number of viable cells in culture based on the quantitation of adenosine triphosphate (ATP) present, which signals the presence of metabolically active cells. After the treatment, the cells are incubated with $20 \mu \mathrm{L}$ of Cell Titre-Glo ${ }^{\mathrm{TM}}$ reagent and contents are allowed to mix on an orbital shaker in accordance with the assay protocols. This results in cell lysis and generation of a luminescent signal proportional to the amount of ATP present. The amount of ATP is proportional to the number of cells present in culture. The luminescence signal is recorded with a single tube luminometer (TD 20/20, Turner Biosystems Inc., Sunnyvale, CA, USA).

\section{Results and discussions Irradiation effect on gold NPs}

Structural and optical properties of gold NPs under gamma irradiation

Figure 1 shows the surface morphology and size distribution of nonirradiated gold NPs, and $4 \mathrm{kR}$ and $10 \mathrm{kR}$ irradiated 

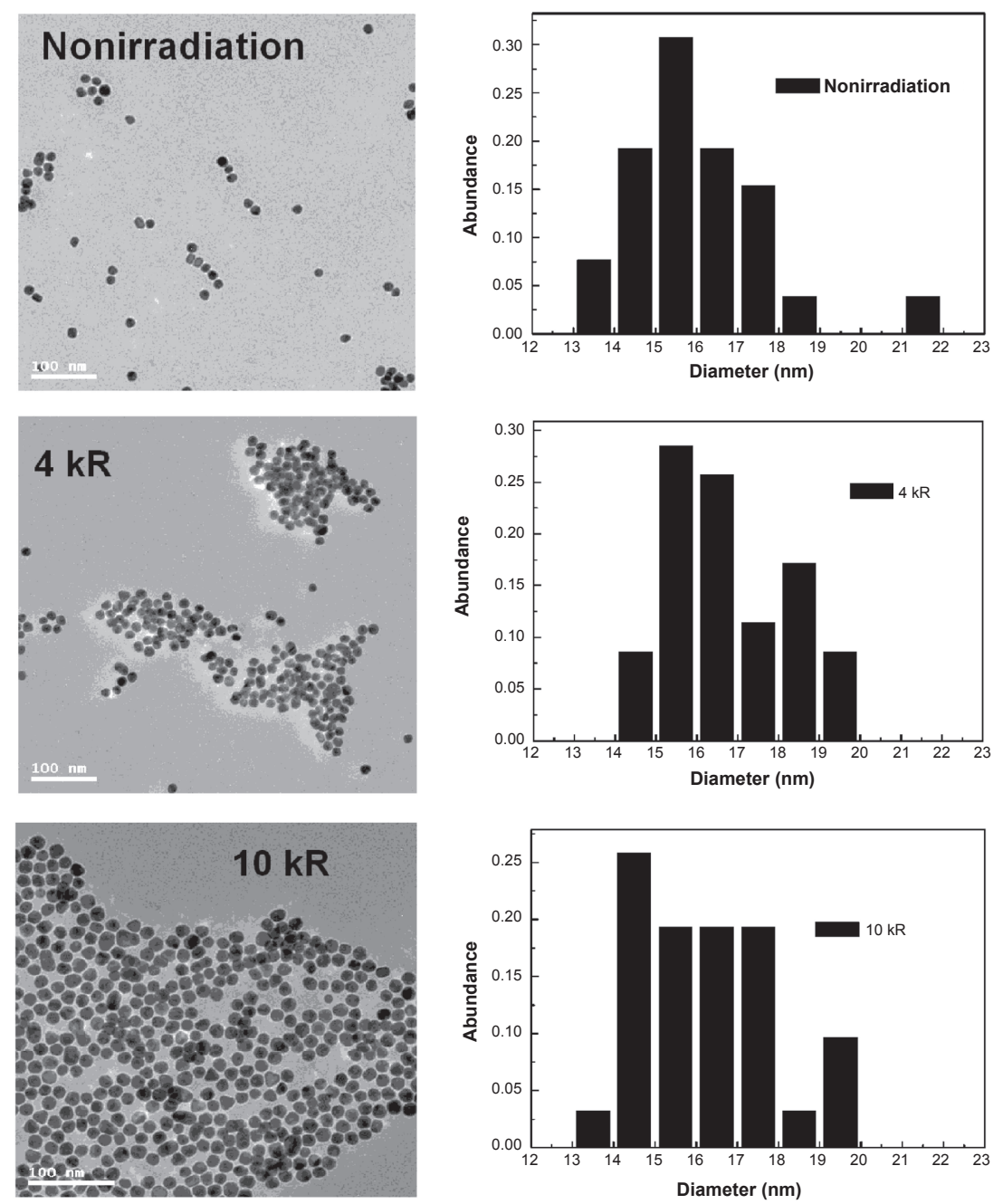

Figure I TEM images of the nonirradiated, 4 and $10 \mathrm{kR}$ irradiated gold NPs. The corresponding size histograms are given.

Abbreviations: NPs, nanoparticles; TEM, transmission electron microscopy.

gold NPs. The shape of gold NPs is nearly spherical, and the standard deviation of size distribution is about $12 \%$ by statistical analysis, which is very close to the previous work. ${ }^{27}$ The average diameters of gold NPs are 15.9, 16.7, and $16.1 \mathrm{~nm}$, which correspond to nonirradiated gold NPs, and $4 \mathrm{kR}$ and $10 \mathrm{kR}$ irradiated gold NPs, respectively, which reveals that gamma irradiation has not induced obvious variation in size. Gachard and colleagues investigated the kinetics properties of $\mathrm{KAuCl}_{4}$ solution with different radiation doses in detail. ${ }^{28}$ The results revealed that gold NPs concentration increased with increased irradiation dose. Actually, the gold ions in the solution are reduced to the metallic state by reacting with hydrated electrons produced as a result of radiolysis of water by the incident gamma ray. When the dose is increased, nucleation of the gold NPs increases up to a limiting value corresponding to the total reduction of the solution. Thus, we can deduce that the slight increase in size may originate from a chemical reaction in rudimental auric solution induced by the irradiation. In addition, we notice that the nonirradiated gold NPs are well dispersed, although slight aggregation is inevitable. Gamma irradiation can induce the aggregation of gold NPs on small scale. Especially, the aggregation of gold NPs irradiated by $10 \mathrm{kR}$ are more obvious than that of $4 \mathrm{kR}$. However, it is necessary to point out that gold NPs do not turn out to be agglomerated in these dose ranges and the distance between gold NPs become closer. It is very interesting to note that similar aggregation phenomenon in gold NPs has been reported under laser irradiation. ${ }^{29}$ Actually, due to the strong photoelectric effect, high energy gamma irradiation can cause lots of surface electrons and charge transfer of gold NPs, which is related to the aggregation of gold NPs. These results also support and explain the recent cell experiment in which unknown aggregation of gold NPs has been observed near the cell membrane after $0.1-1 \mathrm{kR}$ X-ray irradiation. ${ }^{12}$ 
In radiotherapy, the increasing aggregation of gold NPs can induce the enhancement of optical absorption so that radiosensitization and optical imaging of gold NPs can be more effective.

Figure 2 gives the optical absorption of nonirradiated gold NPs, 2, 4, 6, 8, and $10 \mathrm{kR}$ irradiated gold NPs. The SPR band of $521 \mathrm{~nm}$ has been observed in nonirradiated gold NPs, and the peak is not shifted after gamma irradiation. Indeed, the so slight size variation should not induce the obvious shift of SPR peak. Mie theory is the exact solution to Maxwell's electromagnetic field equations for a plane wave interacting with a homogenous sphere of radius with the same dielectric constant as bulk metal. ${ }^{30}$ The size of gold NPs is in good agreement with the results calculated by Mie theory. Group 2 is added in order to illustrate the validity and reproducibility of results, in
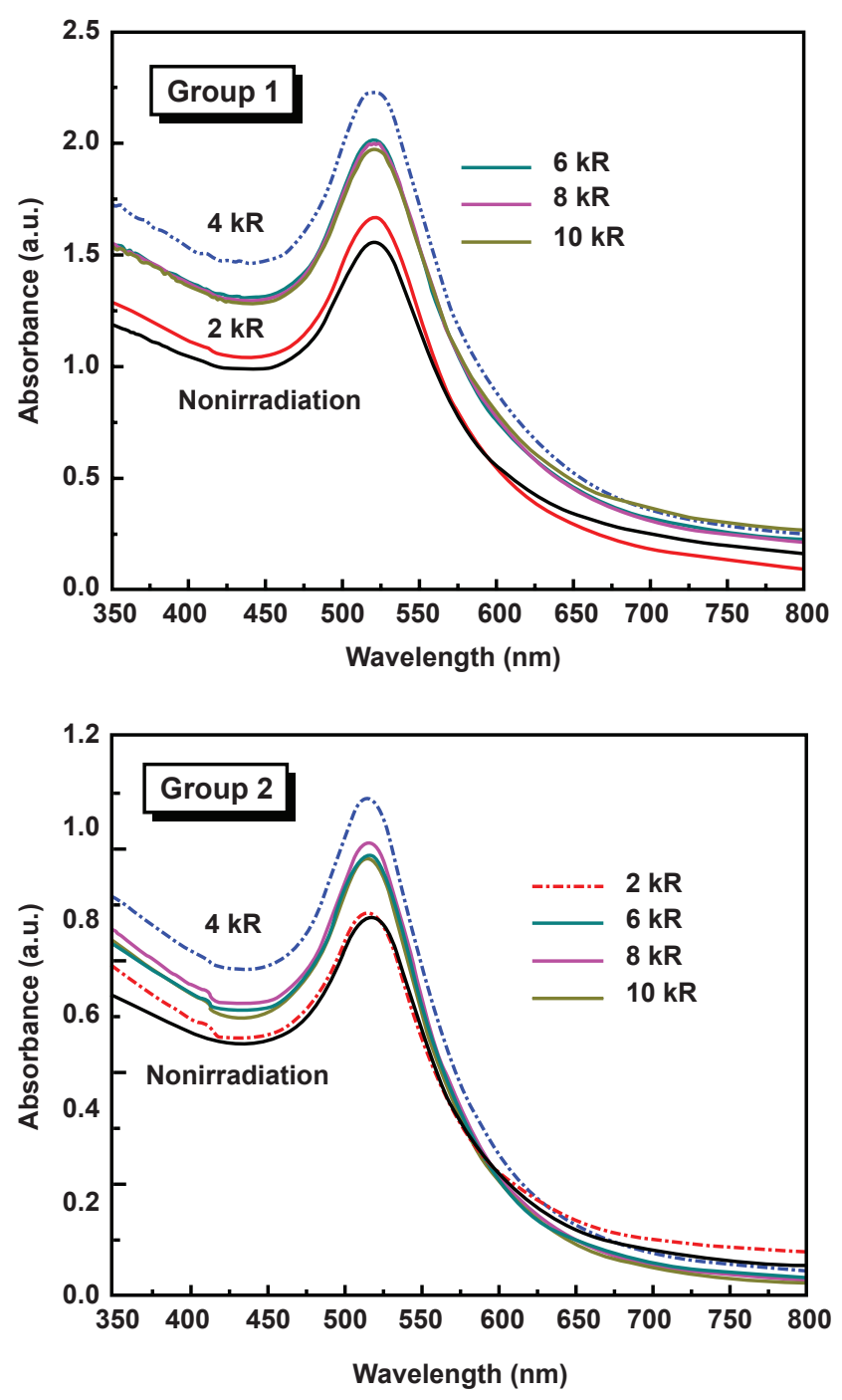

Figure 2 The optical absorption of the nonirradiated, 2, 4, 6, 8, and $10 \mathrm{kR}$ irradiated gold NPs. The gold concentration of group 2 is half of group 1 .

Abbreviation: NPs, nanoparticles. which the concentration of gold NPs is half of group 1. The sole SPR peak in the spectra indicates that gamma irradiation has not caused obvious defects in gold NPs. The full width at half-maximum of the SPR band is about $50 \mathrm{~nm}$, and has no obvious variation after gamma irradiation, which also indicates that gold NPs are very stable after gamma irradiation.

It is worth noting that the SPR peak of gold NPs is enhanced obviously after gamma irradiation. The enhancement of SPR is very obvious at the dose of $4 \mathrm{kR}$ and the enhanced effect is gradually stable above $6 \mathrm{kR}$. Both groups perform good reproducibility. Besides, we have also investigated the optical effect of sodium citrate solution under $2-10 \mathrm{kR}$ irradiation, which has not shown any absorption in the 500-800 nm. This indicates that the enhanced absorption is from the SPR of gold NPs, not the dissolved citrate. Figure 3 shows the enhanced effect of SPR in group 1 of Figure 2. It can be observed that the absorbance of SPR is increased from 1.56 of nonirradiation to 2.23 of $40 \mathrm{kR}$ irradiation, and stabilized to 2.0 in the range of $6-10 \mathrm{kR}$. After normalization, the enhancements of SPR intensity are $10.9 \%, 40 \%, 29.1 \%$, $25.5 \%$, and $23.1 \%$, which correspond to $2,4,6,8$, and $10 \mathrm{kR}$ irradiated doses, respectively. We notice that the high dose irradiations of 6-10 kR have not induced obvious variation in SPR, which indicates that $4 \mathrm{kR}$ may be the optimal energy for SPR modification of gold NPs.

\section{Irradiation mechanism}

The interaction between gamma rays and gold NPs can be classified for photoelectric effect, Compton scattering, electron-positron pairs, and high energy excitation (see Figure 4). ${ }^{31}$ The photoelectric effect mainly occurs in the 10-500 keV range, while electron-positron pairs caused by photon annihilation dominate above $1.02 \mathrm{MeV}$. Thus, the photon of $662 \mathrm{keV}$ mainly falls into Compton scattering and excitation. The results of Compton scattering are re-excitation and photoelectric effect. The high energy excitation can induce lots of phonons and less photons because the dominant transition of gold NPs is photon-phonon transition processing. Thus, gamma irradiation can provide strong energy to gold NPs so that it can be transformed to thermal energy and abundant electron. It is well known that the thermal treatment is a kind of common method to boost nucleation of NPs and enhance SPR. ${ }^{19}$ Laser irradiation is regarded as a good way to enhance the SPR of gold NPs. ${ }^{32}$ By the same mechanism, the thermal effect induced by gamma irradiation can boost nucleation of gold NPs and thus induces enhancement of SPR. ${ }^{33}$ While an abundance of free electrons excited by gamma irradiation can lead to production of surface electrons 

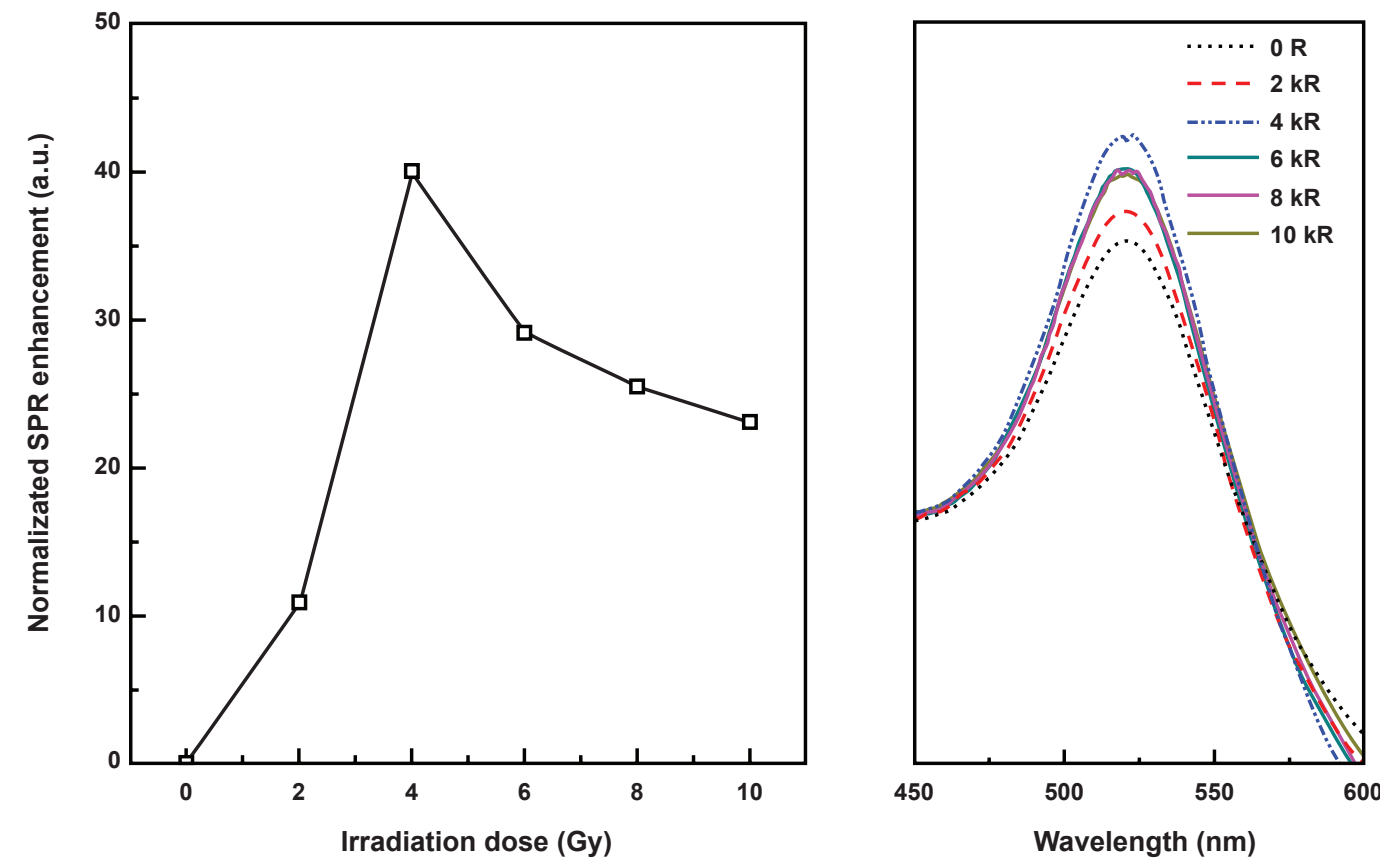

Figure 3 The relative and normalized SPR enhancement of gold NPs dependent on irradiated dose. Abbreviations: NPs, nanoparticles; SPR, surface plasmon resonance.

and charge transfer between gold NPs, which is responsible for SPR enhancement of gold NPs. Moreover, this detailed charge transfer process, such as electron and hole, has been described by the reaction: ${ }^{19,28}$

$$
\mathrm{Au}^{+}+\mathrm{e}^{-} \rightarrow \mathrm{Au}^{0}
$$

Gachard and colleagues proposed that the radiation reactions could be classified as three procedures: (1) radiolytic yields of the radicals in solution, (2) nucleation of NPs, and (3) stabilization processing of NPs. Intense gamma rays cause radiolysis of water in aqueous solutions producing primarily species such as $\mathrm{H}^{+}, \mathrm{H}, \mathrm{HO}, \mathrm{OH}^{-}$and hydrated electrons. ${ }^{28}$ These transient species interact with themselves, water, the solute components, or free radicals generated by irradiation. ${ }^{34}$ Lamaestre and colleagues reported that the nucleation of gold NPs was accelerated by the aggregation of charge and the

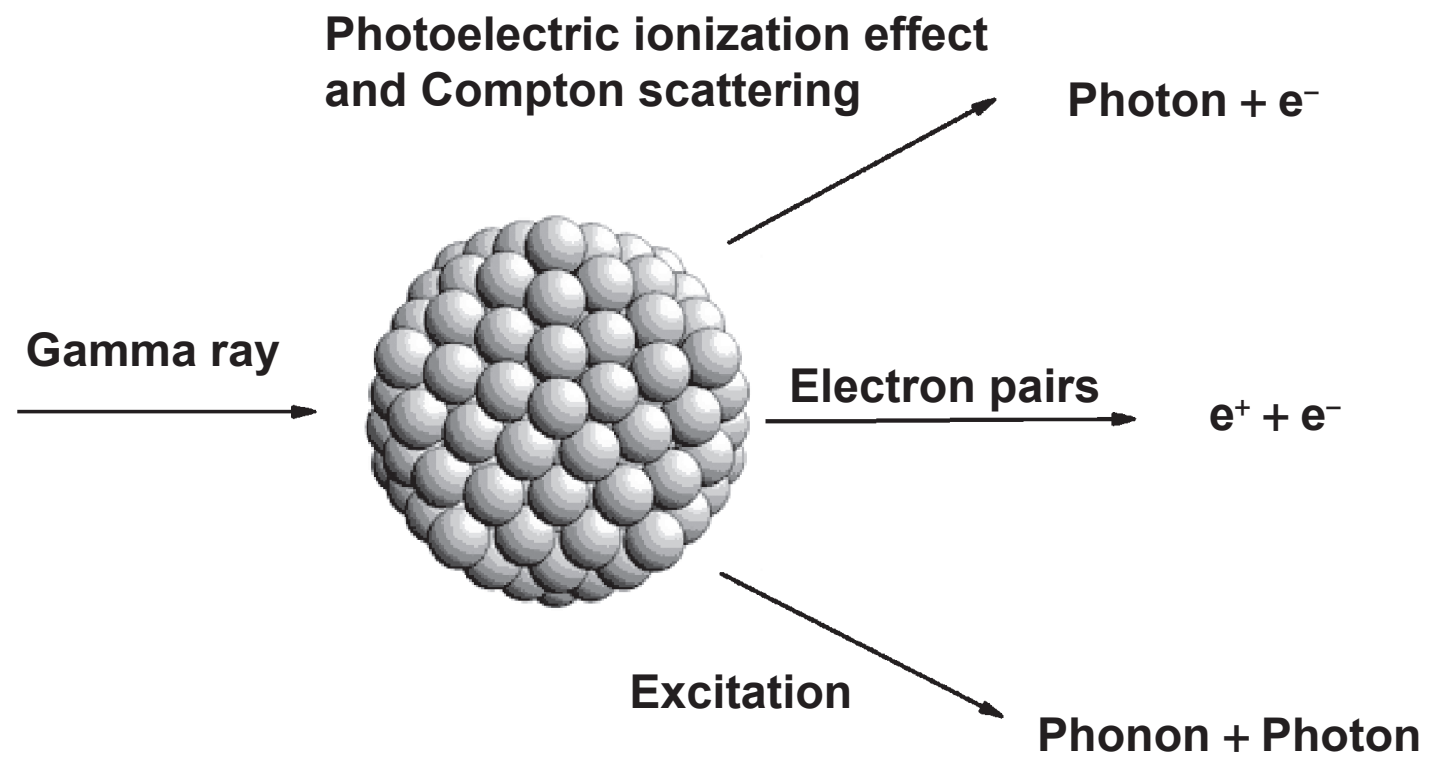

Figure 4 Outline of the interaction between gamma rays and nanoparticles. 
environmental redox potential. ${ }^{35}$ Therefore, we can conclude that 2-4 kR gamma irradiations induce SPR enhancement. However, with an increasing radiation dose, the residual auric solutions may be used up. ${ }^{28}$ Meanwhile, high energy radiation may destroy the chemical bond and cause some damage. ${ }^{28,34,35}$ Thus, 6-10 kR irradiations induce the slight decrease of SPR compared with that of $4 \mathrm{kR}$. Combined with the previous theory and experimental works, we suggest that the high radiation dose may induce partial destruction of the $\mathrm{Au}-\mathrm{Au}$ chemical bond while the low dose irradiation may be helpful for the nucleation of gold NPs. Gamma irradiation is an efficient means of modifying and controlling the system's redox state via charge transfer and transitions between surface charge states and precursors.

\section{Radiation hardness}

The gamma irradiation mechanism of gold NPs is similar to that of QDs. However, the influences of gamma irradiation between QDs compounds and gold NPs seem obviously different. In order to evaluate the irradiation hardness of gold NPs, the exposure dose is converted to the absorbed dose, which is dependent on atomic number $(Z)$ and structure of materials. The absorbed dose $D$ can be described by the following formula: ${ }^{21,31}$

$$
\mathrm{D}=0.88\left[\mu_{e n}(h v) / \rho\right]_{A u} /\left[\mu_{e n}(h v) / \rho\right]_{\text {air }},
$$

where $h v$ is the gamma photon energy and $\left[\mu_{e n}(h v) / \rho\right]$ is the mass energy absorption coefficient for the subscript material. It is well-known that the energy absorption coefficient at $662 \mathrm{keV}$ is about $2.93 \times 10^{-3} \mathrm{~m}^{2} / \mathrm{kg}$ for air and $3.16 \times 10^{-2} \mathrm{~m}^{2} / \mathrm{kg}$ for gold.$^{36}$ Calculated from Eq. 2, the absorbed dose conversation factor for gold NPs is found to be $9.491 \mathrm{rad} / \mathrm{R}$. Compared with the previously reported CdSe QDs of $0.899 \mathrm{rad} / \mathrm{R}$, gold NPs have better radiation hardness. The gamma irradiation in the ranges of $2-10 \mathrm{kR}$ can destroy the chemical bond of QDs and lead to the rapid decomposition of QDs, ${ }^{37}$ while gold NPs have no similar problems in these dose ranges. Thus, it can be expected that gold NPs show good irradiation stability in radiotherapy.

\section{Cytotoxicvity of gold NPs}

The objective of this cell viability study is to assess the cytotoxicity of gold NPs for K562 cells, and further obtain the cytotoxicity curve. Cell Titer-Glo ${ }^{\mathrm{TM}}$ luminescent cell viability assay has been used to assess cytotoxicity after culturing in presence of the gold NPs for 48 hours. As is evident in Figure 5, cell viability decreases with increasing gold concentration, which indicates that the cytotoxic

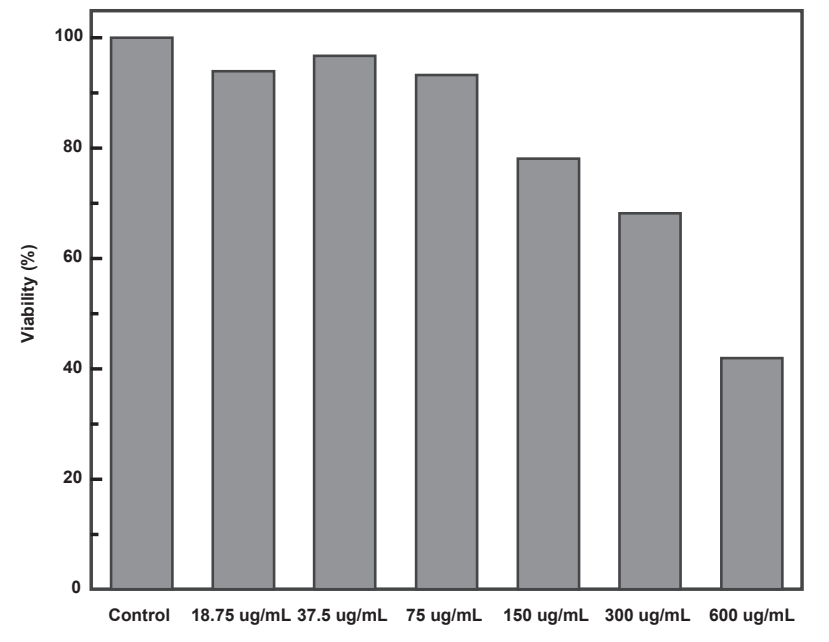

Figure 5 Cytotoxicity of gold NPs with different concentrations and incubation with K562 cells after 48 hours.

Abbreviation: NPs, nanoparticles.

effect of gold NPs increases. It can be observed that the low concentration gold $(<75 \mu \mathrm{g} / \mathrm{mL})$ has not affected the cell viability obviously, and has no obvious cytotoxicity. However, the high concentration gold ( $>150 \mathrm{mg} / \mathrm{mL})$ can indicate the slight decrease of cell viability. In detail, cell viabilities are 93.9\%, 96.7\%, 93.3\%, 77.5\%, 68.8\%, and $41.8 \%$, which correspond to $18.75,37.5,75,150$, 300 , and $600 \mu \mathrm{g} / \mathrm{mL}$ gold, respectively. In addition, the cytotoxicity of phosphate-buffered saline has also been checked in Figure 6, and it has not shown cytotoxicity. The results indicate that gold NPs have obvious cytotoxicity in high concentrations, which is in good agreement with the recent results..$^{25,38}$

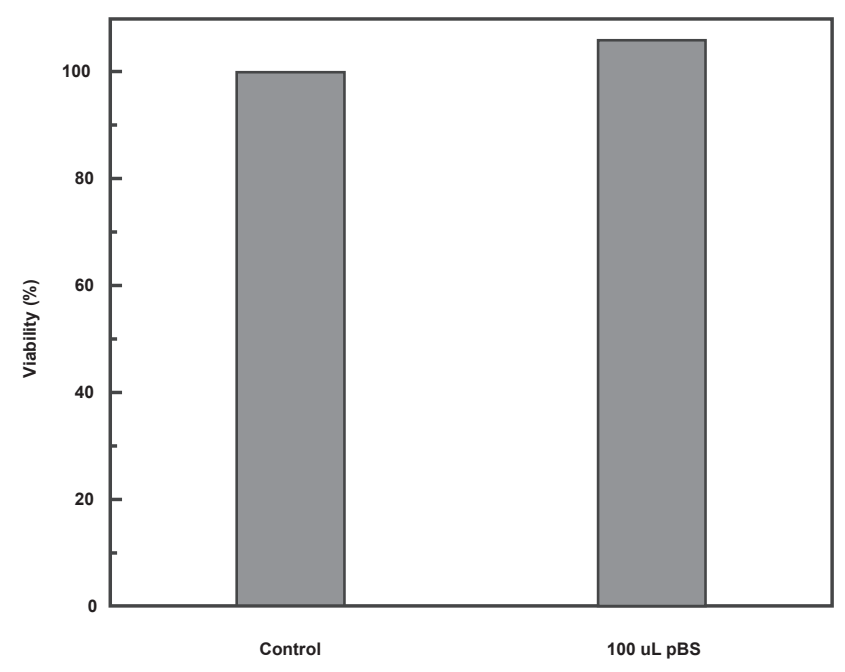

Figure 6 Cytotoxicity of PBS buffer and incubation with K562 cells after 48 hours. Abbreviation: PBS, phosphate-buffered saline. 
Several groups examined the cytotoxicity of gold NPs. The consensus is that gold NPs are safe at low concentrations. However, the results are still controversial and conflicting at high concentrations. Recent reviews highlighted the size, shape, and concentration-dependent cytotoxicity of gold NPs..$^{38-40}$ We summarized some recent cytotoxicity tests of gold NPs in Table 1. Connor and colleagues examined the uptake and potential toxicity of a series of gold NPs in human leukemia cells. ${ }^{24}$ The results indicated gold NPs were nontoxic and its surface modifiers showed cytotoxicity, which was in good agreement with the results of Goodman ${ }^{23}$ and Patra ${ }^{41}$ This cytotoxicity could be related to the electrostatic adsorption between the cationic NPs and the negatively charged cell membranes. In addition, cytotoxicity of gold NPs also depends on the types of cells. For example, gold NPs were found to be noncytotoxic to baby hamster kidney and human hepatocellular liver carcinoma cells, but cytotoxic to a human carcinoma lung cell line at certain concentrations. ${ }^{38} \mathrm{~A}$ similar inconsistency has been found between human-Chinese hamster ovary (CHO) cells and human dermal fibroblast cell lines. Size and shape also play an important role in cytotoxicity of gold NPs. Chan and colleagues examined the uptake of gold NPs of various sizes and shapes into HeLa cells and found that $50 \mathrm{~nm}$ spheres were taken up more quickly by the cells than both smaller and larger spheres. ${ }^{44}$ Meanwhile, Pan and colleagues reported that $15 \mathrm{~nm}$ gold NPs had good biocompatibility while $1.5 \mathrm{~nm}$ gold NPs could cause the acute toxicity of fibroblasts, epithelial cells, macrophages, and melanoma cells. ${ }^{45}$

Actually, nearly anything can be toxic at a high enough concentration. Pernodet and colleagues confirmed that a high concentration of gold NPs showed strong decrease of cell proliferation, adhesion, and motility in the human dermal fibroblast cells, which is consistent with our results. ${ }^{25}$ We find that gold NPs show concentration-dependent cytotoxicity, although $15 \mathrm{~nm}$ gold particles showed good biocompatibility in previous investigations. The cytotoxicity of gold NPs is more important at the potential concentrations where they might be used. In radiotherapy, gold concentration may be as high as $7 \mathrm{mg} / \mathrm{mL}$. Besides, gamma irradiation can induce abundant electrons, which may influence the cellular selectivity of gold NPs. The time-dependent cytotoxicity effect of gold NPs is still not clear, and the toxicity study in vivo also becomes more and more important. Thus, the further toxicity of gold NPs should be essential before radiotherapy sensitization and drug delivery.

\section{Conclusions}

In summary, the stability test and SPR-enhanced effect of gold NPs exposed in gamma irradiation have been investigated. The results show that gamma irradiation cannot induce obvious size variations in gold NPs under 2-10 kR irradiation. Meanwhile, the SPR of gold NPs was enhanced obviously and gamma irradiation did not cause evident defects. Cytotoxicity test shows that high gold concentrations can cause obvious decrease of cell viability while low gold concentrations have no obvious influence on the cell viability. Gold NPs are a stable material for radiotherapy and drug delivery. However, further cytotoxicity tests in vivo is still necessary before high-concentration gold NPs can be used in radiotherapy.

\section{Acknowledgments}

Authors would like to thank Professors Liang-An Zhang, Shu-Yu Yuan, and Ti-Qiang Fan for providing sample

Table I Summary of the cytotoxicity of gold nanoparticles

\begin{tabular}{|c|c|c|c|c|}
\hline Group & Size $(\mathrm{nm})$ & Cell line & Concentrations & Cell viability \\
\hline Connor ${ }^{24}$ & $4,12,18$ & K562 human leukemia & $25-250 \mu \mathrm{M}$ & Nontoxicity \\
\hline Goodman ${ }^{23}$ & 2 & Mammalian cells & $0.38-3 \mu \mathrm{M}$ & Obvious cytotoxicity \\
\hline Patra $^{41}$ & 33 & BHK2I, Hep2G, and A549 human cells & $10-120 \mathrm{nM}$ & Selective cytotoxicity \\
\hline $\mathrm{Liu}^{12}$ & $4-6$ & Mice CT26 cells & $250-500 \mu \mathrm{M}$ & Nontoxicity \\
\hline Male ${ }^{42}$ & $5-6$ & Human V79 cells & $45 \mu \mathrm{M}$ & Nontoxicity \\
\hline Zhang ${ }^{43}$ & 15 & Human $\mathrm{CHO}$ cells & $0.01-100 \mu \mathrm{g} / \mathrm{mL}$ & Nontoxicity \\
\hline Pernodet $^{25}$ & 14 & Human dermal fibroblast cells & $100-800 \mu \mathrm{g} / \mathrm{mL}$ & Serious toxicity \\
\hline Chithrani ${ }^{44}$ & $10-100$ & HeLa cells & & \\
\hline $\operatorname{Pan}^{45}$ & $1.5-15$ & Fibroblasts, epithelial cells & $30-56 \mu \mathrm{M}$ & Selective cytotoxicity \\
\hline Our work & 15 & K562 human leukemia mammalian cells & $10-600 \mu \mathrm{g} / \mathrm{mL}$ & Selective cytotoxicity \\
\hline
\end{tabular}


fabrications, measurements, and some helpful discussions. We also received cellular experimental assistance from the Tianjin Key Laboratory of Molecular Nuclear Medicine. This work is supported by the Specialized Research Fund for the Doctoral Program (SRFDP) of Higher Education State Education Ministry (Grant No. 200800231058), and Subject Development Foundation at the Institute of Radiation Medicine, CAMS (Grant No. SR0632).

\section{References}

1. Daniel MC, Astruc D. Gold nanoparticles: assembly, supramolecular chemistry, quantum-size-related properties, and applications toward biology, catalysis, and nanotechnology. Chem Rev. 2004; 104:293-346.

2. Eustis S, El-Sayed MA. Why gold nanoparticles are more precious than pretty gold: Noble metal surface plasmon resonance and its enhancement of the radiative and nonradiative properties of nanocrystals of different shapes. Chem Soc Rev. 2006;35:209-217.

3. Hu M, Chen J, Li ZY, et al. Gold nanostructures: engineering their plasmonic properties for biomedical applications. Chem Soc Rev. 2006;35:1084-1094.

4. Anker JN, Hall WP, Lyandres O, Shah NC, Zhao J, Van Duyne RP. Biosensing with plasmonic nanosensors. Nat Mater. 2008; 7:442-453.

5. Sokolov K, Follen M, Aaron J, et al. Real-time vital optical imaging of precancer using anti-epidermal growth factor receptor antibodies conjugated to gold nanoparticles. Cancer Res. 2003;63: 1999-2004.

6. Link S, El-Sayed MA. Shape and size dependence of radiative, non-radiative and photothermal properties of gold nanocrystals. Int Rev Phys Chem. 2000;19:409-453.

7. Pissuwan D, Valenzuela SM, Cortie MB. Therapeutic possibilities of plasmonically heated gold nanoparticles. Trends Biotechnol. 2006;24:62-67.

8. Zheng J, Zhang C, Dickson RM. Highly fluorescent, water-soluble, size-tunable gold quantum dots. Phys Rev Lett. 2004;93(7):077402.

9. Huang X, El-Sayed IH, Qian W, El-Sayed MA. Cancer cell imaging and photothermal therapy in the near-infrared region by using gold nanorods. J Am Chem Soc. 2006;128:2115-2120.

10. Hainfeld JF, Slatkin DN, Smilowitz HM. The use of gold nanoparticles to enhance radiotherapy in mice. Phys Med Biol. 2004;49: N309-N315.

11. Juzenas P, Chen W, Sun YP, et al. Quantum dots and nanoparticles for photodynamic and radiation therapies of cancer. Adv Drug Deliv Rev. 2008;60:1600-1614.

12. Liu CJ, Wang CH, Chien CC, et al. Enhanced X-ray irradiation-induced cancer cell damage by gold nanoparticles treated by a new synthesis method of polyethylene glycol modification. Nanotechnology. 2008;19:295104-295109.

13. Davidson AT, Kozakiewicz AG, Comins JD. Photoluminescence and the thermal stability of color centers in $\gamma$-irradiated $\mathrm{LiF}$ and $\mathrm{LiF}(\mathrm{Mg})$. J Appl Phys. 1997;82:3722-3729.

14. Gu HE, Qi L, Wan LF. Broadly tunable yellow green laser using color centers in a LiF crystal at room temperature. Appl Phys Lett. 1988;52:1845-1847.

15. Gu HE. Low-temperature optical spectra and zero-phonon transitions of color centers in $\gamma$-rayed sodium fluoride crystals. Chin Phys Lett. 1993;10:543-546.

16. Hu X, Fang J, Wang Q, et al. A deep level induced by gamma irradiation in $\mathrm{Hg}_{1-\mathrm{x}} \mathrm{Cd}_{\mathrm{x}} \mathrm{Te}$. Appl Phys Lett. 1998;73:91-93.

17. Zhang XD, Liu CL, Wang Z, Lü YY, Yin LJ. Photoluminescence and electrical properties of N-implanted ZnO films. Nucl Instrum Methods Phys Res B. 2007;254:83-86.
18. Chung GY, MacMillan MF, Baca AG, Briggs RD, Schoenfeld D, Pearton SJ. Comparison of stability of WSi/SiC and Ni/SiC Schottky rectifiers to high dose gamma-ray irradiation. Appl Phys Lett. 2004;84:371-373.

19. Agnello S, Nuccio L. Thermal stability of gamma-irradiation-induced oxygen-deficient centers in silica. Phys Rev B. 2006;73:115203.

20. Agnello S, Boscaino R, Cannas M, Gelardi FM, Leone M. $\gamma$-ray-induced bleaching in silica: Conversion from optical to paramagnetic defects. Phys Rev B. 2000;61:1946-1951.

21. Withers NJ, Sankar K, Akins BA, et al. Rapid degradation of CdSe/ZnS colloidal quantum dots exposed to gamma irradiation. Appl Phys Lett. 2008;93:173101.

22. Nel A, Xia T, Mädler L, Li N. Toxic potential of materials at the nanolevel. Science. 2006;311:662-627.

23. Goodman CM, McCusker CD, Yilmaz T, Rotello VM. Toxicity of gold nanoparticles functionalized with cationic and anionic side chains. Bioconjugate Chem. 2004;15:897-900.

24. Connor EE, Mwamuka J, Gole A, Murphy CJ, Wyatt MD. Gold nanoparticles are taken up by human cells but do not cause acute cytotoxicity. Small. 2005;1:325-327.

25. Pernodet N, Fang X, Sun Y, et al. Adverse effects of citrate/gold nanoparticles on human dermal fibroblasts. Small. 2006;2:766-773.

26. Turkevich J, Stevenson PC, Hillier J. A study of the nucleation and growth processes in the synthesis of colloidal gold. Discuss Faraday Soc. 1951;11:55-75.

27. Link S, El-Sayed MA. Size and temperature dependence of the plasmon absorption of colloidal gold nanoparticles. J Phys Chem B. 1999; 103:4212-4217.

28. Gachard E, Remita H, Khatouri J, Keita B, Nadjo L, Belloni J. Radiation-induced and chemical formation of gold clusters. New J Chem. 1998;22:1257-1265.

29. Mafune F, Kohno J, Takeda Y, Kondow T. Dissociation and aggregation of gold nanoparticles under laser irradiation. J Phys Chem B. 2001;105:9050-9056.

30. Link S, Burda C, Nikoobakht B, El-Sayed MA. Laser-induced shape changes of colloidal gold nanorods using femtosecond and nanosecond laser pulses. J Phys Chem B. 2000;104:6152-6163.

31. Attix FH. Introduction to Radiological Physics and Radiation Dosimetry. New York, NY: Wiley; 1986. p. 155.

32. Halabica A, Idrobo JC, Pantelides ST, Magruder RH, Pennycook SJ, Haglund RF. Pulsed infrared laser annealing of gold nanoparticles embedded in a silica matrix. J Appl Phys. 2008; 103:083545.

33. Zhang XD, Liu CL, Guo ML, et al. Structural and optical properties of $\mathrm{Cu}$ nanoparticles embedded in $\mathrm{Si}_{3} \mathrm{~N}_{4} / \mathrm{Si}$ by ion implantation. Opt Mater. 2008;30:1382-1386.

34. Jayanetti S, Mayanovic RA, Anderson AJ, Bassett WA, Chou IM. Analysis of radiation-induced small $\mathrm{Cu}$ particle cluster formation in aqueous $\mathrm{CuCl}_{2}$. J Chem Phys. 2001;115:954-962.

35. Lamaestre RE, Béa H, Bernas H, Belloni J, Marignier JL. Irradiationinduced Ag nanocluster nucleation in silicate glasses: Analogy with photography. Phys Rev B. 2007;76:205431.

36. Davisson CM, Eavns RD. Gamma-ray absorption coefficients. Rev Mod Phys. 1952;2:79-107.

37. Cheung DT, Perelman N, Tong D, Nimni ME. The effect of $\gamma$-irradiation on collagen molecules, isolated $\alpha$-chains, and crosslinked native fibers. J Biomed Mater Res. 1990;24:581-589.

38. Lewinski N, Colvin V, Drezek R. Cytotoxicity of nanoparticles. Small. 2008;4:26-49.

39. Murphy CJ, Gole AM, Stone JW, et al. Gold nanoparticles in biology: beyond toxicity to cellular imaging. Acc Chem Res. 2008;41:1721-1730.

40. Teeguarden JG, Hinderliter PM, Orr G, Thrall BD, Pounds JG. Particokinetics in vitro: dosimetry considerations for in vitro nanoparticle toxicity assessments. Toxicol Sci. 2007;95:300-312.

41. Patra HK, Banerjee S, Chaudhuri U, Lahiri P, Dasgupta A. Cell selective response to gold nanoparticles. Nanomedicine. 2007;3: 111-119. 
42. Male KB, Lachance B, Hrapovic S, Sunahara G, Luong JH. Assessment of cytotoxicity of quantum dots and gold nanoparticles using cell-based impedance spectroscopy. Anal Chem. 2008;80:5487-5493.

43. Zhang WQ, Lu Y, Zhang TK, Xu W, Zhang M, Yu SH. Controlled synthesis and biocompatibility of water-soluble $\mathrm{ZnO}$ nanorods/ $\mathrm{Au}$ nanocomposites with tunable UV and visible emission intensity. JPhys Chem C. 2008;112:19872-19877.
44. Chithrani BD, Ghazani AA, Chan WCW. Determining the size and shape dependence of gold nanoparticle uptake into mammalian cells. Nano Lett. 2006;6:662-668.

45. Pan Y, Neuss S, Leifert A, et al. Size-dependent cytotoxicity of gold nanoparticles. Small. 2007;3:1941-1949.

International Journal of Nanomedicine

\section{Publish your work in this journal}

The International Journal of Nanomedicine is an international, peerreviewed journal focusing on the application of nanotechnology in diagnostics, therapeutics, and drug delivery systems throughout the biomedical field. This journal is indexed on PubMed Central, MedLine, CAS, SciSearch $\AA$, Current Contents ${ } /$ Clinical Medicine,

\section{Dovepress}

Journal Citation Reports/Science Edition, EMBase, Scopus and the Elsevier Bibliographic databases. The manuscript management system is completely online and includes a very quick and fair peer-review system, which is all easy to use. Visit http://www.dovepress.com/ testimonials.php to read real quotes from published authors.

Submit your manuscript here: http://www.dovepress.com/international-journal-of-nanomedicine-journal 